\title{
PROCESSO SAÚDE DOENÇA DAS MULHERES COM CÂNCER CÉRVICO UTERINO NAS REDES DE ATENÇÃO
}

Magali A. Alves de MORAES ${ }^{1}$

Amira Kheireddine SALEH ${ }^{2}$

Ana Cláudia Perez MARTINS 3

Camilla Passarela SILVA³

Florence Seabra DOURADO 3

Lidiani Mara da SILVA²

Vanessa de Sousa MELO²

Altiva Ayko NISHIURA ${ }^{4}$

Ariane Vernaschi AMBONATI ${ }^{5}$

Edileuza Maria de SOUZA ${ }^{6}$

\footnotetext{
${ }^{1}$ Doutora em Educação pela UNESP de Marília, docente da Famema - SP- coordenadora do grupo PET-Redes de atenção à saúde - dmagalimoraes@ hotmail.com.

${ }^{2}$ Graduanda de Medicina pela Famema - SP.

${ }^{3}$ Graduanda de Enfermagem pela Famema - SP.

${ }^{4}$ Médica, Secretaria Municipal de Saúde de Marília - SP.

${ }^{5}$ Enfermeira, Famema - SP.

${ }^{6}$ Assistente Social, Famema - SP.
}

Recebido em: 10/08/2015 - Aprovado em: 06/01/2016 - Disponibilizado em: 30/07/2016

\begin{abstract}
Resumo
Objetivos: Analisar o processo saúde doença das mulheres com câncer cérvico uterino, o acesso às redes de atenção à saúde e caracterizar o perfil dessas mulheres atendidas na atenção terciária. Método: Estudo epidemiológico do tipo transversal quanti-qualitativo. Para análise quantitativa, foram utilizados prontuários para o preenchimento de 183 questionários de mulheres com câncer de colo uterino no período de 2010 a 2013, atendidas pelo SUS em um hospital do interior do Estado de São Paulo. Os dados foram analisados e apresentados em porcentagens, seguida de análise descritiva. Para análise qualitativa, foram realizadas 11 entrevistas e utilizada a técnica de análise de conteúdo, modalidade temática. Resultados e conclusões: A média de idade das mulheres com câncer cérvico uterino foi de 53 anos, sendo a maioria casada (47,5\%), com ensino fundamental completo (29\%), branca (78,8\%) e do lar (42,6\%) e esperaram até três meses para o início do tratamento. A notícia do diagnóstico é impactante, devido ao estigma negativo do câncer e de seu tratamento. A descoberta da doença desencadeia um processo complexo de reações psicossociais, tanto para a mulher, como para aqueles que constituem suas redes sociais, principalmente familiares e amigos mais próximos. As redes de apoio são fundamentais para o enfrentamento e superação de todo o processo. É necessário melhorar a educação em saúde quanto à importância da realização anual de Papanicolaou e também os aspectos de humanização e empatia na relação profissional de saúde-paciente.
\end{abstract}

Palavras-chave: Câncer de colo do útero. Saúde da mulher. Redes de atenção. Redes de apoio. Educação em saúde.

\section{Health and disease process of women with cervical cancer in the care network}

\author{
Abstract \\ Objectives: The aim of this study was to analyze the health and disease process of women with uterine cervical cancer \\ and the access to the SUS care networks, as well to characterize the profile of women with cervical cancer who are
}


attended in tertiary care, identify his life story and the disease process. Methodology: Epidemiological study crosssectional quantitative and qualitative. For quantitative analysis 183 questionnaires were filled with dice of women who had cervical cancer over the past three years, with results presented as simple frequency, followed by descriptive analysis. For qualitative analysis were made 11 interviews, recorded and transcribed, followed by qualitative analysis with content analysis technique, thematic modality. Results and conclusions: The mean age of women with uterine cervical cancer was 53 years, and the majority was married $(47,5 \%)$, with completed elementary school (29\%), white $(78,8 \%)$ and housewife $(42,6 \%)$. The news of the diagnosis is impressive due to the negative stigma of cancer and its treatment. The discovery of the disease triggers a complex process of psychosocial, emotional and affective reactions, both for women as for those who are their social networks, mainly family and close friends. Support networks are key for facing and overcoming the whole process. It is necessary to improve health education on the important of conducting annual Papanicolaou and also aspects of humanization and empathy in the relationship health professionalpatient.

Keywords: Uterine cervical neoplasms. Women's Health. Networks of attention. Support networks. Health education.

\section{Introdução}

Segundo o Instituto Nacional de Câncer (INCA) o câncer de colo de útero é a quarta causa de mortalidade das mulheres e o terceiro mais incidente na população feminina brasileira. (BRASIL, 2015).

Cerca de $80 \%$ das mulheres sexualmente ativas será contaminada pelo Papilomavírus Humano (HPV) em sua vida e quando há a persistência de um subtipo viral oncogênico, lesões precursoras do câncer podem ocorrer. Portanto infecção pelo HPV é um fator necessário para o câncer, nesse sentido, a prevenção do HPV pode minimizar a incidência. Desde 2014, o Ministério da Saúde adicionou ao calendário vacinal a quadrivalente contra o HPV para meninas de 9 a 13 anos. A vacinação e o exame do Papanicolaou são ações de prevenção contra este tipo de câncer. (BRASIL, 2015).

Mas outros fatores de risco estão relacionados ao aparecimento deste câncer. (BRASIL, 2015).
Essa pesquisa se direcionou ao perfil das mulheres com câncer de colo do útero, atendidas na atenção terciária; ao acesso aos serviços de saúde e como vivenciaram o processo de adoecer e o tratamento. Compreender as percepções dessas mulheres sobre o processo saúde doença é fundamental para implementar o cuidado à saúde.

\section{Método}

Estudo epidemiológico do tipo transversal quantitativo e qualitativo. $\mathrm{Na}$ análise quantitativa foi realizada a caracterização do perfil das mulheres atendidas na rede de atenção terciária pelo SUS, considerando o acesso à rede. Foram preenchidos 183 questionários com os dados de prontuários das pacientes com câncer do colo de útero, no período de 2010 a 2013, na atenção terciária em um município no interior do Estado de São Paulo. Os períodos estipulados para a coleta foram consensuados por especialistas da área e se justificam pela incidência do respectivo quadro. 
Após a coleta dos dados estes foram digitados em planilhas de Excel 2010 for Windows e apresentados em porcentagens, seguida de análise descritiva.

Para a análise qualitativa foram realizadas onze entrevistas com essas mulheres. A técnica utilizada foi a da história de vida tópica, focalizando a etapa do adoecimento e tratamento. Na sequência, a análise de conteúdo, modalidade temática . (MINAYO, 2010). As entrevistas foram interrompidas pela saturação das falas. Para garantir o sigilo, as falas das participantes receberam a letra $\mathrm{P}$, seguida de um número.

Todo o procedimento foi realizado após a aprovação do Comitê de Ética em Pesquisa da Famema, parecer consubstanciado n. 500.189 em 18/12/2013 e as participantes assinaram o termo de consentimento livre e esclarecido.

\section{Resultados e Discussão}

Constatou-se que o perfil das mulheres atendidas na atenção terciária, tem a idade média de 53 anos, 47,5\% casadas, 78,8\% brancas, $98,9 \%$ residem em cidades que pertencem a DRS IX, 29\% possuem ensino médio completo e $42,6 \%$ são do lar. Considera-se que a idade média está de acordo com o levantado por Santos et al. (2012) e o risco da doença aumenta com a idade, atingindo o seu pico entre 50 e 60 anos.
Observou-se ainda que a maioria delas $19,7 \%$ já teve 5 ou mais partos vaginais; $15,8 \%$ nenhum; $14,8 \%$ dois e $49,7 \%$ outras quantidades de partos. Segundo Stofler, Nunes e Schneider (2011) as multíparas, mais que quatro partos, tem maior chance em desenvolver o câncer de colo do útero. Os diagnósticos foram realizados por biopsia (76,5\%), $12 \%$ por conização, $4,9 \%$ por outros tipos e 6,6\% dados desconhecidos. A maioria das mulheres esperaram até 3 meses para o início do tratamento, tempo razoável, pois isso facilita a intervenção e está próximo do previsto pela lei 12.732/2012. (LABOISSIÈRE, 2013). O tratamento mais frequente foi a quimioterapia associada à radioterapia 26,8\%; 20,8\% realizou somente o tratamento cirúrgico; $15,8 \%$ radioterapia e cirúrgico; $31,8 \%$ outro tipo de tratamento e $4,9 \%$ desconhecidos. O tipo de tratamento dependerá do estadiamento da doença e fatores pessoais. (BRASIL, 2015).

A tabela 1 apresenta os dados que foram pouco encontrados nos prontuários e tiveram a sua porcentagem calculada como dados desconhecidos. 
TABELA 1 - DADOS COLETADOS DOS PRONTUÁRIOS CONSIDERADOS DESCONHECIDOS-2014

\begin{tabular}{lc} 
DADOS COLETADOS & \% DESCONHECIDOS \\
\hline MENARCA & 39,9 \\
SEXARCA & 50,8 \\
NUMERO DE PARCEIROS & 60,1 \\
CICLO MENSTRUAL & 51,9 \\
MENOPAUSA & 33,3 \\
METODO CONTRACEPTIVO & 47,0 \\
DATA DO ULTIMO PAPANICOLAOU & 41,0 \\
RESULTADO DE PAPANICOLAOU 1 & 85,2 \\
RESULTADO DE PAPANICOLAOU 2 & 47,0 \\
HISTORIA PESSOAL & 42,1 \\
HISTORIA FAMILIAR - & \\
ANTECEDENTES DE NEOPLASIAS & 41,5 \\
TEMPO DE ESPERA PARA & \\
CONFIRMAÇÃO DE DIAGNOSTICO & 25,1 \\
\hline Fonte: próprios autores & \\
\hline
\end{tabular}

A ausência de dados nos prontuários pode acarretar prejuízo na assistência as pacientes, pois, faz-se necessário o levantamento da história clínica da paciente, cujas perspectivas são a prevenção de doenças e a promoção da saúde e da melhoria da qualidade de vida das mesmas. (BERTOCCHI et al., 2014). Quando os prontuários são preenchidos de maneira inadequada, além do comprometimento à assistência ao paciente, compromete também a instituição e os profissionais envolvidos (SETZ; D’INNOCENZO, 2009).

Em relação à análise do conteúdo das 11 entrevistadas foram elencadas cinco categorias temáticas, apresentadas a seguir:

\section{A história da descoberta da doença e o acesso à rede de atenção.}

De acordo com Carvalho et al. (2006) a maioria das mulheres com câncer cérvico uterino são assintomáticas, mas podem ter sintomas como corrimento vaginal aquoso, fétido, sangramento vaginal espontâneo ou induzido (pós-coito), aumento do fluxo menstrual e dor pélvica. Como os relatos:

“[...] começou com uns corrimentos.” P10

“Tinha parado aos 44 anos [...] Ai com 59, começou a descer pra mim. [...] Ai começou a parar e vinha uma água, um líquido fedido, meio esverdeado e grosso e fedido [...] e uma dor que me doía aqui do lado." P1

Nota-se, também, a falta de informação de algumas mulheres com relação aos sinais e sintomas sugestivos do câncer, o que retarda a busca por tratamento. Como visto na fala:

"No começo, no final do ano pra cá eu comecei a sentir dor... só que aí eu fui deixando... mas, eu tinha um sangramento, alguma coisinha assim... e eu tinha uns corrimentos também." P6

No que se refere à realização do Papanicolaou as participantes falam:

“[...] eu fiz umas três vezes Papanicolau, não adiantou nada." P1

“[...] Eu já fiz uma vez, mas faz uns 2 anos que eu não fazia. E ai o Dr. me falou que tinha dado uma feridinha no útero ai ele passou aquela pomada lá. E eu não fui atrás, foi descuido meu." P2

Essas falas indicam que ora a realização do exame é negligenciada, ora é 
vista como algo que não evita o câncer, como referido por P1. Além da fala de P2 que elucida a desinformação e falta de conscientização da paciente com a sua saúde.

\section{Segundo Cruz e Loureiro (2008)} pouca adesão ao exame de Papanicolaou, aumenta as chances da descoberta da doença em estágios mais avançados, com redução da sobrevida e aumento nos custos para o tratamento.

A divulgação da importância do Papanicolaou foi criticada pela P8:

"[...]em 2009 quando apareceu aquilo lá tivessem falado pra mim 'ó, você tem que fazer isso, tem que fazer os exames anual pra gente ver como é que tá indo, se não vai dar mais, se já sarou...' então era outra coisa. Então eu senti falha nessa parte, né.[...]." $P 8$

Em relação ao acesso à rede a lei $n^{\circ}$ 12.732 dispõe que após a confirmação diagnóstica de câncer, o tratamento deverá iniciar em um prazo de até 60 dias, dependendo das necessidades biológicas da paciente (BRASIL, 2012).

$\mathrm{Na}$ opinião das mulheres esse tempo de 60 dias para o início do tratamento tem sido respeitado. Todavia, a ansiedade quanto à resolução da doença é um elemento que faz parecer demorado o início do tratamento :

“Começo de março... então demorou mais ou menos, quase dois meses [...] quase dois meses pra poder tá retornando nele pra ver esse resultados de exame e ele encaminhar eu pra começar a fazer a Quimio e a Radio [...] tava demorando demais [...].” P8
Entretanto, houve relatos que consideraram rápido $\mathrm{o}$ tempo entre $\mathrm{o}$ diagnóstico e o tratamento:

"Ai foi rápido porque eu fiz no finalzinho de abril... comecinho de maio né... e ele marcou para 3 de junho a cirurgia." $\mathrm{P6}$

Casarin e Piccoli (2011) elucidam que a descoberta precoce desse câncer pode gerar uma cura de $100 \%$ e tratamentos ambulatoriais em $80 \%$ dos casos. Santos, Moreno e Pereira (2009) referem que podem ocorrer resultados falsos negativos no exame preventivo, inerente a falhas ocorridas na coleta do material ou no procedimento laboratorial; retardando o tratamento $\mathrm{e}$ podendo aumentar as chances para o câncer. Fato relatado abaixo:

“[...] Depois de muito tempo, comecei a ter sangramento e voltei no ginecologista. Ai ele fez Papanicolaou e uns três exames e não constatou nada [...]." P11

"Aí eu pedi pra moça encaminhar eu pro ginecologista e eu perguntava pra ela se dava alguma alteração nos exames de Papanicolau e ela falava que não [...].” P10

Várias participantes reclamam do atendimento dos profissionais de saúde, da desorganização e negligência pública, da demora e da dificuldade ao acesso às redes do SUS, as quais podem acarretar em um retardo no diagnóstico e tratamento:

“Aí foi passando o tempo... ele pediu alguns exames. Eu já tinha feito os exames, mas não estava constando os exames direitinho. Aí da última vez que ele me pediu e disse que não sabia o que eu tinha mais uma vez, eu procurei particular. " $P 9$ 
“Passei no clínico, não tinha ginecologista lá. Passei no clínico, e ele me encaminhou para um ginecologista. Isso em fevereiro. Não fui encaminhada até hoje no ginecologista. " P6

Algumas participantes elogiam o atendimento na atenção terciária, mas reclamam da organização pública de seu município e do acolhimento:

“Ai eu achei que foi rápido [atenção terciária], porque do jeito que demora né, eu achei que foi rápido. Porque eu fui pra Assis, porque se estivesse lá [cidade de residência] eu ainda estava esperando ainda [...]." P6

É necessário, portanto, facilitar o acesso das mulheres às redes de atenção e fornecer orientações sobre sua saúde e prevenção.

\section{Reação pessoal, de familiares e amigos}

diante da doença, do tratamento e perspectivas futuras.

Quanto à reação pessoal, o diagnóstico representa uma notícia que assusta, não só a mulher, como também seus familiares e amigos, principalmente pelo estigma do câncer e do seu tratamento.

“Porque essa palavra [câncer] assusta né?" P3

"[...] aí ela pegou e deu a notícia pra mim né, uma notícia, a gente não tava esperando isso né, pra mim isso era uma feridinha no útero, uma coisa assim né, mas não que era um câncer. ” P8

Outra fala recorrente, diz respeito ao enfrentamento da doença, principalmente quanto ao medo da morte. Pode haver uma negação da doença em um primeiro momento, mas o que mais ocorre é uma tentativa de entender, adaptar-se e conviver com a doença e o tratamento que agora lhe foi imposto. (OLIVEIRA; FERNANDES; GALVÃO, 2005).

"Fui me acostumando que eu ia passar mal na quimioterapia, que... tudo isso do tratamento. Aí eu fui me acostumando com tudo." P9

\section{"No começo a gente desanima. A gente não quer} acreditar, a gente não aceita. Ué, porque comigo e não cusotro. $O$ zotro faz coisa errada e não acontece nada. [...] mas agora não. Agora já acostumei, já.” P10

Quanto à reação de familiares e amigos, assim como as participantes, nota-se que eles recebem a notícia como um choque e carregam o estereótipo do tratamento difícil, do sofrimento e da possibilidade da morte (XAVIER; GENTILI, 2012).

“Eles ficaram sabendo, foi um desespero.” P7

“Ah! na hora todo mundo ficou assustado, né. Porque minha vó morreu com isso né." P10

No que se refere às perspectivas futuras uma delas já começa a pensar o que fará quando se recuperar:

“Eu penso [voltar a trabalhar]. Que DEUS vai me dá a segunda chance né! " P3

São escassos ainda os trabalhos sobre o período pós-tratamento do câncer cérvico uterino e suas repercussões na reinserção psicossocial das pacientes, mas, Rossi e Santos (2003, p. 40) afirmam que "no momento pós-tratamento, aparecem as repercussões no plano afetivo-sexual e 
também as dificuldades de adaptação à nova situação de vida, com limitações físicas e restrições, embora também sejam reconhecidas as mudanças positivas trazidas pela experiência de terem passado pelo câncer".

\section{Redes de apoio}

É recorrente a repetição de 'Deus' e da fé como grandes aliados de uma boa evolução no tratamento. A fé é como uma energia propulsora, que traz juntamente com a crença em Deus, a esperança de ter a cura da doença (LINARD; SILVA; SILVA, 2002). A fé em Deus atua como elemento positivo no enfrentamento da doença e nesse âmbito é interpretada como uma estratégia para lidar com as incertezas da doença e superar as situações de crise vivenciadas.

“Então, graças a Deus já comecei fazer o tratamento [...] e graças a Deus também eu já to sentindo uma diferença boa, [...] e graças a Deus, então eu to vendo o resultado [...]. Então, me ajudou muito, a fé, a fé, a crer [...]. " $P 8$

Outra rede de apoio é a família que, quando bem orientada, mostra-se essencial, podendo inclusive crescer como grupo social, a partir do amadurecimento emocional de cada um. É importante para a mulher, ao enfrentar o câncer, fortalecer o vínculo afetivo com os filhos e com o parceiro, possibilitando amparo e apoio. (XAVIER; GENTILLI, 2012).

"Meus filhos vieram, ficaram comigo, me deram força pra eu erguer, minhas noras, agora minha menina veio semana passada, pra ficar tomando conta da casa e acompanhar eu. " P1

Rodrigues e Ferreira (2012, p.786) ressaltam que "nem sempre a família consegue assumir todo o cuidado, necessitando contar com a ajuda de outros, tal apoio, advindo da rede de amigos, é eficiente, sobretudo no aspecto emocional e na execução de cuidados práticos.".

“[...]É, amigos né, que nessas horas a gente vê as pessoas que são realmente nossos amigos né [...]. ” P8

As redes de apoio, têm sua relevância, inclusive para o enfrentamento da doença.

\section{Repercussões da doença na autoestima, na relação sexual e afetiva, e no trabalho.}

Somado ao estigma do câncer, e ao medo de morrer, há o fato do útero estar ligada à capacidade de reprodução, algo tão importante para a sensação do pertencimento ao sexo feminino.

Segundo Pimentel et al. (2011, p.260) “[...] o câncer pode acarretar alterações significativas nas diversas esferas da vida como trabalho, família e lazer. Dessa forma, acaba trazendo implicações em seu cotidiano e nas relações com as pessoas do seu contexto social.".

Desde o início do tratamento, as pacientes passam por alterações em suas vidas, como o emagrecimento, a abstinência sexual, o afastamento do trabalho e em alguns 
casos a queda de cabelo. Sendo assim, a mulher tem que lidar com mudanças abruptas em seu cotidiano como a proibição do uso de alguns produtos químicos afetando a vaidade e a auto-estima das pacientes.

“Bom, mulher é vaidosa, né... [riso] a parte minha do cabelo, aí meu pai, não posso mexer [...].” P9

Durante o tratamento também, a ânsia por sobreviver é tão intensa, que a necessidade sexual acaba sendo deixada de lado. (FERRARI; HERZBERG, 1998).

Em relação à repercussão do tratamento na vida sexual, uma das participantes revela:

"[...] em relação a mim e meu marido, a gente não tem relação e tal, por causa do problema, então isso abala um poquinho, né. Mas graças a Deus, meu marido também é uma pessoa compreensiva, nossa é um amor e ele me ajuda muito nessa parte [...].” P8

Isso mostra o quanto à aceitação do parceiro frente à impossibilidade de ter relações sexuais ajuda a paciente a enfrentar a situação. Entretanto, nem sempre o parceiro aceita a indicação médica.

Segundo Linard, Silva e Silva (2002, p.497): "Desistir de algumas atividades diárias ou simplesmente ter consciência de não ser capaz de realizá-las, é um processo vivenciado com dificuldade por muitas mulheres com câncer, levando algumas destas a se sentirem como um objeto inútil." Portanto, a duração do tratamento e a debilidade causada por ele faz com que a maioria delas tenha que se afastar de seus empregos, privando-se as de suas tarefas cotidianas e seu convívio diário, como desabafa a participante:

"Tá sendo horrível, horrível, horrível [ficar sem trabalhar]. Desde os 14 anos que eu trabalho. Não vejo a hora de voltar." P2

\section{A qualidade do atendimento na visão das pessoas com câncer cérvico uterino}

Após receber o diagnóstico de câncer, a paciente precisa se sentir segura para se submeter a um tratamento tão agressivo. Por isso, o profissional de saúde deve esclarecer acerca de todas as etapas do tratamento e de todos os efeitos colaterais que podem ocorrer. Silva et al. (2011, p. 1458) destacam que: "Por se tratar de uma doença percebida como traumatizante, perante o imaginário pessoal e coletivo, sua abordagem torna-se especialmente difícil. Angústias, medos e sofrimentos apresentam-se na vida dos pacientes e de suas famílias, necessitando estabelecer um vínculo com o profissional como coadjuvante terapêutico."

Algumas pacientes revelaram 0 descaso pelos profissionais de saúde, retardando o diagnóstico.

“Ai eu fui passar pela ginecologista, fui levar o resultado pra ela... Ela olhou e disse que não era caso pra cirurgia. Porque eu estava tendo hemorragia por causa do meu peso, porque eu estava 'muito gorda'. Ela falou assim pra mim. Ela passou outro anticoncepcional pra mim e me ofereceu pra eu fazer aquela bariátrica." P2 
Quanto à comunicação dos profissionais de saúde, as opiniões divergem de uma comunicação direta e fria: "Aí eu passei pelo médico... Ele foi curto e grosso: 'Você está com Câncer no Colo do Útero!!'[...]." P10. A outra comunicação elogiada pela participante é atribuída à orientação do seu médico: "Ai ele [médico] falou assim: 'não fica triste, mas eu sei que é duro...' Ai ele falou pra mim que tinha tratamento, que eu ia ficar boa [...]." P2

Algumas pacientes também relataram que não receberam informações suficientes sobre o tratamento, como revela a P10:

"Tiraram um pedaço do colo do útero. Foi o que me falaram né. Porque, até agora, ninguém me deu satisfação de nada... Agora, se é realmente isso, eu não sei. Porque ninguém me deu uma explicação." P10

Ferrari e Herzberg (1998, p. 30) destacam que: "É comum o paciente ter vergonha da sua ignorância sobre assuntos que julga serem óbvios para o médico". Desta forma, as pacientes muitas vezes deixam de esclarecer dúvidas com os médicos por sentirem vergonha ou não se sentirem à vontade de questioná-los. Ou ainda, por não quererem saber naquele momento.

"Não sei, porque não falaram nada. [a respeito de fazer quimioterapia] [...] Nem quero saber ainda, porque eu creio em Deus que não vai precisar!” P10.

Nesse sentido, quanto à qualidade do atendimento e do tratamento a maioria se mostrou satisfeita, como a P7:

"Mas aqui eles também atendem bem, [...] todo mundo muito educado, paciente com a gente. " P7
Uma das falas demonstra o quão importante foi à orientação fornecida a ela sobre a sua patologia, através de palestras:

"Comecei a vir ali [Ambulatório de Ginecologia] $e$ escutando aquelas palestras; elas falando: 'não precisa ter medo né. A gente tem que lutar pela gente [...] Aí, depois disso eu comecei a encarar a vida de outra forma." P3

Dessa forma, a qualidade do atendimento dos profissionais está relacionada à comunicação empática, ao acolhimento das dúvidas e preocupações e ao fornecimento de informações as pacientes.

\section{Conclusão}

Ao final deste estudo, conclui-se que poucos dados do perfil puderam ser caracterizados pela falta de informação nos prontuários. $\mathrm{O}$ tempo de espera entre diagnóstico e tratamento está próximo dos 60 dias preconizado. A falta de dados nos prontuários compromete a realização de pesquisas e pode inclusive prejudicar a assistência; e ações precisam ser tomadas para reverter esta situação.

As falas das entrevistadas sobre seu processo saúde doença valorizaram a comunicação empática e as redes de apoio. Reforçaram a importância da educação em saúde para a prevenção e esclarecimentos sobre o câncer e o seu tratamento. 
Agradecimentos aos outros membros do grupo PETredes de atenção à saúde que colaboraram na coleta de dados: Caio Vinicius da Conceição; Daniela Esteves Temporim; Janaina Dias da Silva; Lívia Garcia; Nathalie Arnez Torchia e Pedro Casagranda de Camargo e as preceptoras Glenda Groeschel; Maria Isabel D. Sulpicio e Sandra R. A. M. Mesquita.

\section{Referências}

BERTOCCHI, F. M. et al. Conduta de profissionais durante a consulta de rastreio do câncer de mama e útero. Rev. Rene, Fortaleza, v. 15, n. 6, p. 973-979, nov./dez. 2014. Disponível em:

<http://www.revistarene.ufc.br/revista/index.p $\mathrm{hp} / \mathrm{revista} /$ article/view/1803/pdf $>$. Acesso em: 25 jun. 2014.

BRASIL. Lei $\mathrm{n}^{\circ} 12.732$, de 22 de novembro de 2012. Dispõe sobre o primeiro tratamento de paciente com neoplasia maligna comprovada e estabelece prazo para seu início. Diário Oficial da União, Brasília, DF, 23 nov. 2012. Disponível em:

<http://www.planalto.gov.br/ccivil_03/_ato20 11-2014/2012/lei/112732.htm>. Acesso em: 10 jan. 2015.

BRASIL. Ministério da Saúde. Instituto Nacional de Câncer José Alencar Gomes da Silva. Controle do câncer do colo do útero. Rio de Janeiro, 2015. Disponível em: <www.inca.gov.br>. Acesso em: 13 mar. 2015.

CARVALHO, R. et al. Carcinoma de células escamosas microinvasivo: relato de caso.

Rev. Para. Med. Belém, v. 20, n. 3, p. 65-69, jul./set. 2006.

CASARIN, R. M.; PICCOLI, J. C. E. Educação em saúde para prevenção do câncer de colo do útero em mulheres do município de Santo Ângelo/RS. Cienc. Saúde Coletiva, Rio de Janeiro, v. 16, n. 9, p. 3925-3932, 2011.

CRUZ, L. M. B.; LOUREIRO, R. P. A comunicação na abordagem preventiva do câncer do colo do útero: importância das influências histórico-culturais e da sexualidade feminina na adesão às campanhas. Saúde Soc. São Paulo, v. 17, n. 2, p. 120-131, 2008. Disponível em: <http://www.scielo.br/pdf/sausoc/v17n2/12.p df $>$. Acesso em: 10 jan. 2015.

FERRARI, C; HERZBERG, V. Tenho câncer; e agora?: enfrentando o câncer sem medos e fantasias. São Paulo: Sociedade Brasileira de Oncologia Clínica, 1998.

LABOISSIÈRE, P. Lei 12.732/12, que garante início de tratamento de câncer em 60 dias, entra em vigor dia 23/05/2013.

EcoDebate, Mangaratiba, 17 maio 2013. Disponível em: <http://www.ecodebate.com.br/2013/05/17/lei -12-73212-que-garante-inicio-de-tratamentode-cancer-em-60-dias-entra-em-vigor-dia23052013/>. Acesso em: 27 mar. 2015.

LINARD, A. G.; SILVA, F. A. D; SILVA, R. $M$. Mulheres submetidas a tratamento para câncer de colo uterino: percepção de como enfrentam a realidade. Rev. Bras. Cancerol., Rio de Janeiro, v. 48, n. 4, p. 493-498, 2002.

MINAYO, M. C. S. O desafio do conhecimento: pesquisa qualitativa em saúde. 12. ed. São Paulo: Hucitec; 2010.

OLIVEIRA, M. S.; FERNANDES, A. F. C; GALVÃO, M. T. G. Mulheres vivenciando o adoecer em face do câncer cérvicouterino. Acta Paul. Enferm., São Paulo, v. 18, n. 2, p. 150-152, abr./jun. 2005.

PIMENTEL, A. V. et al. Percepção da vulnerabilidade entre mulheres com diagnóstico avançado do câncer do colo do útero. Texto Contexto Enferm., Florianópolis , v. 20, n. 2, p. 255-262, jun. 2011.

RODRIGUES, J. S. M.; FERREIRA, N. M. L. A. Estrutura e funcionalidade da rede de apoio social do adulto com câncer. Acta Paul. Enferm., São Paulo, v. 25, n. 5, p. 781-7, 2012.

ROSSI, L.; SANTOS, M. A. Repercussões psicológicas do adoecimento e tratamento em mulheres acometidas pelo câncer de 
mama. Psicol. Cienc. Prof., Brasília, v. 23, n. 4, p. 32-41, dez. 2003.

SANTOS, M. L.; MORENO, M. S.;

PEREIRA, M. E. Exame de Papanicolau: qualidade do esfregaço realizado por alunos de enfermagem. Rev. Bras. Cancerol. Rio de Janeiro, v. 55, n. 1, p. 19-25, 2009.

SANTOS, A. L. A. et al. Avaliação da qualidade de vida relacionada à saúde em pacientes com câncer do colo do útero em tratamento radioterápico. Rev. Bras.

Cancerol., Rio de Janeiro, v. 58, n. 3, p. 507515, 2012.

SETZ, V. G.; D'INNOCENZO, M. Avaliação da qualidade de registros de enfermagem no prontuário por meio da auditoria. Acta Paul. Enferm., São Paulo, v. 22, n. 3, p. 313-317, 2009.

SILVA, C. M. G. C. H. et al. Relação médicopaciente em oncologia: medos, angústias e habilidades comunicacionais de médicos na cidade de Fortaleza (CE). Cienc. Saúde Coletiva, Rio de Janeiro, v. 16, p. 1457-1465, 2011. Suplemento 1.

STOFLER, M. E. C. W ; NUNES, R. D, SCHNEIDER, I. J. C. Avaliação de fatores associados às lesões HPV induzidas do colo uterino. Arquivos Catarinenses de Medicina, v. 40, n. 3, p. 84-89, 2011.

XAVIER, B. B.; GENTILLI, R. M. L. Afetos e cooperação familiar como coadjuvantes do tratamento de câncer de mama em mulheres. Serv. Soc. Rev., Londrina, v. 14, n. 2, p. 7395, jan./jun. 2012. Disponível em:

<file:///C:/Users/helenacl/Downloads/1275654949-1-PB.pdf>. Acesso em: 10 jan. 2015. 